\title{
LARYNGEAL MALIGNANCY: A RETROSPECTIVE DESCRIPTIVE ANALYSIS
}

\author{
G. Vinod Kumar' ${ }^{1}$ Balakrishnan Ramaswamy², D. R. Nayak ${ }^{3}$ \\ ${ }^{1}$ Assistant Professor, Department of ENT, Apollo Institute of Medical Sciences \& Research, Hyderabad. \\ 2Professor, Department of ENT, Kasturba Medical College, Manipal. \\ 3 Professor, Department of ENT, Kasturba Medical College, Manipal.
}

\begin{tabular}{l}
\hline ABSTRACT \\
\hline BACKGROUND \\
Laryngeal cancer is the second most common head and neck cancer in India. The onset, rate of progression and duration of \\
symptoms are variable for supraglottic, glottic and subglottic cancer. Smoking and alcohol are also most important risk factors for \\
laryngeal cancer. Data regarding cases of laryngeal cancer in relation to age, sex, symptoms and signs, aetiological factors with special \\
reference to smoking and alcohol, histopathological types, tumour staging, treatment and outcomes are important to assess changing \\
trends in laryngeal cancer treatment.
\end{tabular}

\section{MATERIALS AND METHODS}

This study is about retrospective descriptive analysis of diagnosed and treated cases of laryngeal cancer in the Department of ENT from 2005 to 2008. Total fifty patients with laryngeal malignancy were seen from May 2005 to May 2008 with average 1 year of follow-up. Data regarding cases of laryngeal cancer in relation to age, sex, symptoms and signs, aetiological factors with special reference to smoking and alcohol, histopathological types, tumour staging, treatment and outcomes were analysed using SPSS software. All patients who were diagnosed to have laryngeal cancer and treated were included in the study.

\section{RESULTS}

In this descriptive analysis, 62\% patients are between 51-70 years. Most of the patients had been symptomatic for 3-5 months; $58 \%$ patients presented with voice change followed by other complaints like throat pain, foreign body sensation, otalgia, breathing difficulty. Voice change was distinctly the most common symptom regardless of tumour site. It was more prevalent in glottis cases, but it was also the leading symptom in supraglottic tumours. Glottis tumours were more often found at an early stage and patients with a supraglottic tumour presented more often with neck node metastasis.

\section{CONCLUSION}

Laryngeal malignancy is one of the head and neck malignancies, which are more common in males. Tobacco is an important risk factor in causation of the laryngeal malignancy. Patient usually presents with voice change. Voice change is the most common presenting symptom in glottic cases than supraglottis. Squamous cell carcinoma is most common type and moderately differentiated squamous cell carcinoma is most common variety. As laryngeal cancer is a public health problem with early detection and increasing the awareness of smoking hazards, it is possible to decrease the incidence of laryngeal cancer.

\section{KEYWORDS}

Laryngeal Malignancy, Tobacco, Descriptive Analysis, Laryngeal Cancer, Laryngeal Growth.

HOW TO CITE THIS ARTICLE: Kumar GV, Ramaswamy B, Nayak DR. Laryngeal malignancy: a retrospective descriptive analysis. J. Evolution Med. Dent. Sci. 2016;5(50):3203-3206, DOI: 10.14260/jemds/2016/743

\section{INTRODUCTION}

Laryngeal cancer is the most common non-cutaneous head and neck malignancy. In India it accounts for about $4.3 \%$ of all new cancers in males and $0.67 \%$ in females. The current annual age-adjusted incidence is about 4.1 (Indian cancer registry 2002). The incidence rates vary widely, but a marked predominance of men is a world-wide observation.

Tobacco smoking and high consumption of alcohol are generally regarded as major risk factors for laryngeal cancer [IARC 1986, IARC 1988]. Some environmental, occupational and dietary factors may also play role in a laryngeal carcinogenesis.

Financial or Other, Competing Interest: None.

Submission 08-04-2016, Peer Review 02-06-2016,

Acceptance 07-06-2016, Published 22-06-2016.

Corresponding Author:

Dr. G. Vinod Kumar

Plot No. 136, S. P. Colony,

Trimulgherry, Secunderabad-500015,

Telangana.

E-mail: drvinnu2004@yahoo.co.in

DOI: $10.14260 /$ jemds $/ 2016 / 743$
Over $90 \%$ of laryngeal malignancies are squamous cell carcinomas. For classification purposes the larynx is divided into three anatomical regions; the supraglottis, the glottis and subglottis. Subglottic tumours are rare, comprising only a few percent of all laryngeal malignancies. The glottis to supraglottic location ratio varies in different reports.

This study was conducted to study the aetiopathogenesis of laryngeal cancer with special reference to smoking and alcohol and also to study the clinical features, treatment of the disease and its results.

\section{MATERIALS AND METHODS}

This study was conducted on the patients with laryngeal malignancy attending Department of ENT, Kasturba Hospital, Manipal, during the period May 2005 to May 2008 with average 1 year of followup. It was retrospective descriptive analysis of laryngeal malignancy in the last three years with average 1 year of followup and various variables were studied with respect to the laryngeal malignancy.

A detailed history was recorded in all cases with special reference to aetiological factors like age, sex, occupation and 
tobacco and alcohol consumption. Family history was taken thoroughly to probe about family history of smoking and any family member suffered malignancy.

Any previous history in regards to previous biopsy were documented, any disease for which radiation as treatment modality was used were documented.

While doing outpatient local examination, indirect laryngoscopy was done and the findings were documented with help of the clinical diagrams, lymph nodes were palpated for and documented in reference to its site consistency, mobility and if it is attached to underlying tissue. USG neck was done to assess nodal status. Direct laryngoscopy/Microlaryngoscopy was done in all cases to reconfirm the indirect laryngoscopy findings and biopsy was done to have histopathological confirmation and grade of tumour.

Histopathological confirmation was done with punch biopsy. The histopathological classification was made.(1)

Squamous cell carcinoma: consisting of irregular nests, column or strands of malignant epithelial cells, infiltrating subepithelially. The tumour resembles any or all the layers of stratified squamous epithelium. The squamous cell carcinoma are further subdivided and graded according to differentiation as well differentiated, moderately differentiated and poorly differentiated squamous cell carcinoma. All the patients were staged according to T N M classification and were accordingly staged. Stage 1 and 2 were treated with RT/Laser assisted excision, stage 3 and 4 were treated with combined modality of treatment (Total laryngectomy followed by radiotherapy/chemoradiation.

All the patients evaluated to find out the viability of doing surgery (Total laryngectomy), cross matched blood was made available for surgery, total amount of blood loss, any obvious intraoperative findings were recorded. Patients were on the nasogastric tube in the immediate postoperative period and were started on oral feedings only after 1 week, permanent tracheostomy sutures were removed on postoperative day 14 . Patients were discharged after 2 weeks of surgery. Patients were followed up regularly and after 6 weeks of surgery patients were sent for the radiation depending on the stage. Selected cases were operated using KTP-532 Laser. The patients who underwent either radiation alone or chemoradiation were admitted, planning CT scan was done and routine investigation was done.

Patients planned for concurrent chemoradiation - external beam radiotherapy on Linac $6 \mathrm{MV}$, total dose planned was 66 Grays in 33 fractions over six and half weeks were given.

Chemotherapy planned as 3 weekly chemo sensitizer with Inj. Cisplatin $(100 \mathrm{mg} / \mathrm{m} 2)$ on day 1 , day 22, day 43 was given. All the patients were evaluated and were followed for average of 1 year and symptomatology and condition of primary were recorded and documented.

\section{OBSERVATIONS AND RESULTS}

\section{Sex Distribution:}

All 50 patients are males.

\section{Age Distribution}

Most of the patients are among the age group between 41 years and 70 years of age. There are only 3 patients below the age of 40 and total of 7 patients are more than 70 years of age.

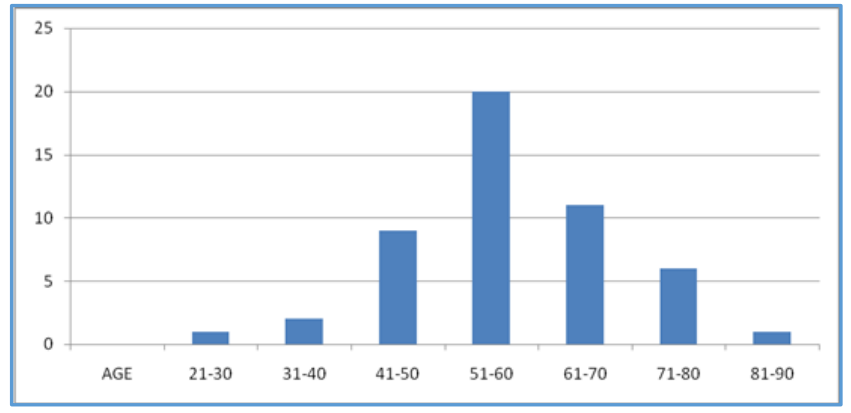

\section{Smoking}

Among the various addictions, smoking is more prevalent; $94 \%$ are smokers and only $6 \%$ were non-smokers. Among smokers, majority are beedi (58\%) smokers, 36\% are cigarette smokers $(18 \%$ are cigarette smokers and $18 \%$ are cigarette+beedi smokers), among cigarette smokers $55.5 \%$ are without filter and $44.5 \%$ are smoking with filter.

Smoking history consisted of the reported number of packs of cigarettes/beedi smoked per day multiplied by the number of years smoking (pack year).

\begin{tabular}{|c|c|c|}
\hline Pack Years & Number & Percent \\
\hline$<1$ & 3 & 6.3 \\
\hline $1-50$ & 27 & 57.4 \\
\hline $51-100$ & 16 & 34.0 \\
\hline $101-150$ & 1 & 2.1 \\
\hline \multicolumn{3}{|c|}{ Table 1 } \\
\hline
\end{tabular}

\section{Alcohol}

$46 \%$ of the patients are alcoholics. Among alcoholics $60.8 \%$ are addicted to cheap liquor and $39.2 \%$ are mixed alcoholics.

\section{Alcohol v/s Smoking}

Total no. of non-smoker and non-alcoholics are 3 (6\%), nonsmoker and alcoholics are 0 , which means all alcoholics are smokers. Total no. of smokers and non-alcoholics are 24 (48\%), 23 (46\%) patients are addicted to both alcohol \& smoking.

\begin{tabular}{|c|c|c|c|c|c|}
\hline & $\begin{array}{c}\text { Non- } \\
\text { Smoker }\end{array}$ & $\begin{array}{c}\text { Cigarette } \\
\text { +Beedi }\end{array}$ & Cigarette & Beedi & Total \\
\hline $\begin{array}{c}\text { Non- } \\
\text { Alcohol }\end{array}$ & 3 & 4 & 6 & 14 & 27 \\
\hline Alcohol & 0 & 5 & 3 & 15 & 23 \\
\hline \multicolumn{6}{|c|}{ Table 2 } \\
\hline
\end{tabular}

\section{Presenting Symptoms}

Out of the 50 patients, $29(58 \%)$ patients had presenting complaint of voice change, $4(8 \%)$ patients had breathing difficulty, $4(8 \%)$ patients had dysphagia, others presented with combination of symptoms.

\begin{tabular}{|c|c|c|}
\hline Symptom & Number & Percent \\
\hline Breathing difficulty & 4 & 8.0 \\
\hline Voice change & 29 & 58.0 \\
\hline Dysphagia & 4 & 8.0 \\
\hline B+V & 3 & 6.0 \\
\hline V+D & 3 & 6.0 \\
\hline OTHERS & 7 & 14.0 \\
\hline Total & $\mathbf{5 0}$ & $\mathbf{1 0 0 . 0}$ \\
\hline \multicolumn{2}{|c}{ Table 3 }
\end{tabular}

B- Breathing difficulty, V-Voice change, D-Dysphagia. 


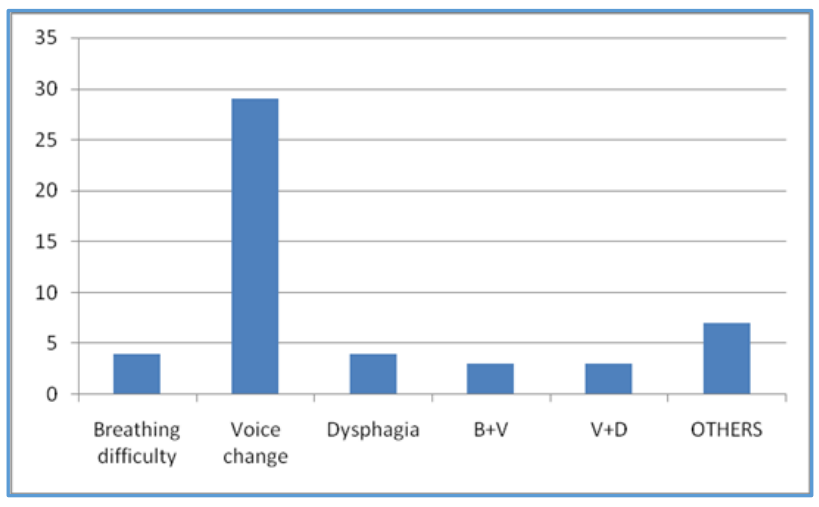

\section{Location}

Out of 50 patients, supraglottic were 29 (58\%), glottis 21 (42\%).

\begin{tabular}{|c|c|c|}
\hline Site & Number & Percentage \\
\hline Supraglottic & 29 & 58 \\
\hline Glottic & 21 & 42 \\
\hline Sub-glottic & 0 & 0 \\
\hline Total & 50 & 100 \\
\hline \multicolumn{3}{|c|}{ Table 4 } \\
\hline
\end{tabular}

\section{Pathological Type}

All 50 patients had squamous cell carcinoma, out of which $42 \%$ are moderately differentiated, $40 \%$ are well differentiated and $14 \%$ are poorly differentiated squamous cell carcinoma. Other 2 are basaloid carcinoma, micro-invasive carcinoma.

\begin{tabular}{|c|c|c|}
\hline & Number & Percentage \\
\hline Well differentiated & 20 & 40 \\
\hline Moderately differentiated & 21 & 42 \\
\hline Poorly differentiated & 7 & 14 \\
\hline Others & 2 & 4 \\
\hline \multicolumn{2}{|c|}{ Table 5 } \\
\hline
\end{tabular}

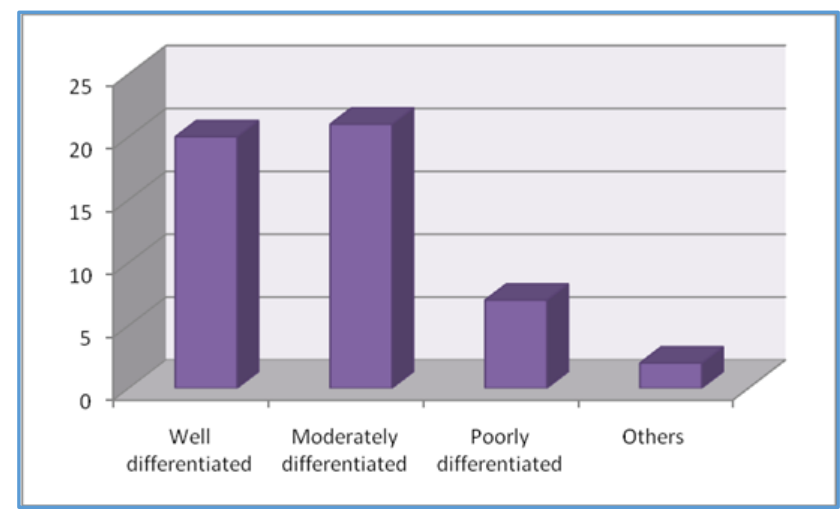

\section{Stage Wise Distribution}

Most of the cases 19 were found to have stage 4, stage 1 and 3 were 11 each, stage 2 were 9 .

\begin{tabular}{|c|c|}
\hline Stage & Number \\
\hline 1 & 11 \\
\hline 2 & 9 \\
\hline 3 & 11 \\
\hline 4 & 19 \\
\hline \multicolumn{3}{|c|}{ Table 6 } \\
\hline
\end{tabular}

\section{Treatment}

Among 50 patients, 14 patients were treated with surgery (Total laryngectomy) followed by radiotherapy, 11 patients were treated with laser (KTP-532) assisted excision, 1 was treated with laser assisted excision followed by chemo RT and 22 patients underwent for chemo-RT, 2 patients treated with RT.

\begin{tabular}{|c|c|}
\hline Treatment & Number \\
\hline Chemo RT & 22 \\
\hline Surgery (Total laryngectomy)+RT & 14 \\
\hline Surgery (Laser) & 11 \\
\hline RT & 2 \\
\hline Surgery (Laser)+chemo RT & 1 \\
\hline Total & 50 \\
\hline \multicolumn{2}{|c|}{ Table 7 }
\end{tabular}

\section{DISCUSSION}

Total fifty patients with laryngeal malignancy were seen from May 2005 to May 2008 with average 1 year of follow-up.

In this descriptive analysis, $62 \%$ patients are between 5170 years. Similar age incidences were reported by Stephenson et al 1991.1

Most of the patients had been symptomatic for 3-5 months. These patients had a high incidence of tobacco consumption in form of beedi and cigarette. Among them $58 \%$ patients were beedi smokers, cigarette only $18 \%$ and cigarette+beedi $18 \%$. This suggests laryngeal malignancy seen in low socioeconomic group (Wynder et al 1976. ${ }^{2}$ Elwood et al 1984. ${ }^{3}$ Kleinsasser 1988.4). No occupational exposure found in this study.

As noted previously in the tables, $58 \%$ patients presented with voice change followed by other complaints like throat pain, foreign body sensation, otalgia, breathing difficulty. The same sequels of presenting symptoms were reported by (Kaufman et al 1980.5 Marck and Lupin 1989.6 Merletti et al $1990 . .^{7}$ Dolan et al 1998.8). Voice change was distinctly the most common symptom regardless of tumour site. It was more prevalent in glottis cases, but it was also the leading symptom in supraglottic tumours.

The proportion of advanced stage lesions was distinctly higher among patients with a supraglottic tumour, but there was no considerable difference in symptom duration between supraglottic and glottis cases. This supports the common opinion that the symptoms appear later in supraglottis cancer (Kleinsasser 1988).

In parallel with previous studies, glottis tumours were more often found at an early stage and patients with a supraglottic tumour presented more often with neck node metastasis. (Stell 1990. ${ }^{9}$, Shah et al 1997, Krecicki et al 1998.10). Supraglottic tumours are generally considered to have poor prognosis than glottic ones. (Lauerma 1967.11, Stell 1990b. ${ }^{12}$, Shah et al 1997.13).

Among 50 patients, 14 patients were treated with combined modality of treatment (total laryngectomy followed by radiotherapy), one patient post-operative, post RT developed pharyngocutaneous fistula. Fistula was closed using PMMC flap. One patient with basaloid carcinoma developed multiple metastasis in liver and adrenals. Another patient following chemo RT developed metastasis in left 3rd rib.

\section{CONCLUSION}

Laryngeal malignancy is one of the head and neck malignancies which are more common in males. As laryngeal 
cancer is a public health problem with early detection and increasing the awareness of smoking hazards, it is possible to decrease the incidence of laryngeal cancer.

Tobacco is an important risk factor in causation of the laryngeal malignancy. Among them 58\% patients are beedi smokers, cigarette only $18 \%$ and cigarette+beedi $18 \%$. Alcohol is an associated risk factor in causation of the laryngeal malignancy; $46 \%$ of the patients are alcoholics. Among alcoholics $60.8 \%$ are addicted to cheap liquor and $39.2 \%$ are mixed alcoholics.

Patient usually presents with voice change. Voice change is the most common presenting symptom in glottic cases than supraglottic. Most of the patients presented in stage 3 and 4 . Direct laryngoscopy/MLS and biopsy is important for the histopathological diagnosis. Squamous cell carcinoma is most common type and moderately differentiated squamous cell carcinoma is most common variety.

\section{REFERENCES}

1. Stephenson WT, Barnes DE, Holmes FF, et al. Gender influences subsite of origin of laryngeal carcinoma. Arch Otolaryngol Head Neck Surg 1991;117(7):774-8.

2. Wynder EL, Covey LS, Mabuchi K, et al. Environmental factors in cancer of larynx: a second look. Cancer 1976;38(4):1591-601.

3. Elwood JM, Pearson JC, Skippen DH, et al. Alcohol, smoking, social and occupational factors in the aetiology of cancer of the oral cavity pharynx and larynx. Int J Cancer 1984;34(5):603-12.
4. Kleinsasser 0. Tumours of the larynx and hypopharynx. George Thieme Verlag, Stuttgart 1988;326-8.

5. Kaufman S, Grabau JC, Lore JM. Symptomatology in head and neck cancer: a quantitative review of 385 cases. Am J Public health1980;70(5):520-2.

6. Marck PA, Lupin AJ. Cancer of the larynx: the north Alberta experience. J Otolaryngol 1989;18(7):344-9.

7. Merletti F, Faggiano F, Boffetta P, et al. Topographic classification, clinical characteristics and diagnostic delay of cancer of the larynx/hypopharynx in Torino, Italy. Cancer 1990;66(8):1711-6.

8. Dolan RW, Vaughan CW, Fuleihan N. Symptoms in early head and neck cancer: an inadequate indicator. Otolaryngol Head Neck Surg1998;119(5):463-7.

9. Stell PM. Prognosis in laryngeal carcinoma: host factors. Clin Otolaryngol 1990;15(2):111-9.

10. Stell PM. Prognosis in laryngeal carcinoma: tumour factors. Clin Otolaryngol 1990;15(1):69-81.

11. Shah JP, Karnell LH, Hoffman HT, et al. Patterns of care for cancer of the larynx in the United States. Arch Otolaryngol Head Neck Surg 1997;123(5):475-83.

12. Krecicki T, Zalesska-Krecicka $M$, Jagas $M$, et al. Laryngeal cancer in Lower Silesia: descriptive analysis of 501 cases. Oral Oncol 1998;34(5):377-80.

13. Lauerma S. Treatment of laryngeal cancer. A study of 638 cases. Acta Otolaryngol 1967;225:1-67. 